\title{
Challenges in digitisation of cultural heritage material in the Western Cape, South Africa
}

\begin{tabular}{|c|c|}
\hline \multicolumn{2}{|c|}{$\begin{array}{l}\text { Authors: } \\
\text { Beatrice de la Porte }{ }^{1} \\
\text { Richard Higgs }^{2}\end{array}$} \\
\hline \multicolumn{2}{|c|}{$\begin{array}{l}\text { Affiliations: } \\
{ }^{1} \text { Cape Town Branch Library, } \\
\text { University of South Africa, } \\
\text { Western Cape Region, } \\
\text { Cape Town, South Africa }\end{array}$} \\
\hline \multicolumn{2}{|c|}{$\begin{array}{l}{ }^{2} \text { Library and Information } \\
\text { Studies Centre, Faculty of } \\
\text { Humanities, University of } \\
\text { Cape Town, Cape Town, } \\
\text { South Africa }\end{array}$} \\
\hline \multicolumn{2}{|c|}{$\begin{array}{l}\text { Corresponding author: } \\
\text { Beatrice de la Porte, } \\
\text { dlporb@gmail.com }\end{array}$} \\
\hline \multicolumn{2}{|c|}{$\begin{array}{l}\text { Dates: } \\
\text { Received: } 11 \text { May } 2019 \\
\text { Accepted: } 06 \text { Aug. } 2019 \\
\text { Published: } 30 \text { Oct. } 2019\end{array}$} \\
\hline \multicolumn{2}{|c|}{$\begin{array}{l}\text { How to cite this article: } \\
\text { De la Porte, B. \& Higgs, R., } \\
2019, \text { 'Challenges in } \\
\text { digitisation of cultural } \\
\text { heritage material in the } \\
\text { Western Cape, South Africa', } \\
\text { South African Journal of } \\
\text { Information Management } \\
21(1) \text {, a1104. https://doi. } \\
\text { org/10.4102/sajim.v21i1. } \\
1104\end{array}$} \\
\hline \multicolumn{2}{|c|}{$\begin{array}{l}\text { Copyright: } \\
\text { (C) 2019. The Authors. } \\
\text { Licensee: AOSIS. This work } \\
\text { is licensed under the } \\
\text { Creative Commons } \\
\text { Attribution License. }\end{array}$} \\
\hline \multicolumn{2}{|l|}{ Read online: } \\
\hline 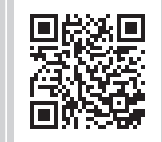 & $\begin{array}{l}\text { Scan this QR } \\
\text { code with your } \\
\text { smart phone or } \\
\text { mobile device } \\
\text { to read online. }\end{array}$ \\
\hline
\end{tabular}

Background: Digitisation of cultural heritage material creates both opportunities and challenges for access and preservation for future generations.

Objectives: Digital cultural heritage can be sustainably preserved and used for information and research purposes if the challenges experienced during digitisation can be identified and addressed by memory institutions.

Method: A quantitative approach was used to analyse challenges for digitisation identified in the literature review. The theory of constraints was used as the theoretical framework for the study. Twenty-eight memory institutions in the City of Cape Town Metropolitan and Cape Winelands District municipalities were selected with non-probability sampling and data were collected with a cross-sectional survey, using a self-administered online questionnaire. Descriptive statistics were used to summarise the data.

Results: The digitisation of cultural heritage material is embraced by memory institutions and a wide variety of cultural heritage material has been selected for digitisation. Memory institutions are following professional or international guidelines, but the lack of a national policy on digitisation has possible consequences for interoperability and limited access. Open access to digitised cultural heritage material is encouraged, but access for use is still limited. The challenges identified in the literature review are experienced by the memory institutions studied, especially those relating to expertise and human resources.

Conclusion: Challenges in digitisation can be addressed with the knowledge of how to manage these constraints. International guidelines and policies can give directives to the management of digitisation if no national or local guidelines exist.

Keywords: Archives; cultural heritage; digitisation; libraries; memory institutions; museums.

\section{Introduction}

The digitisation of cultural heritage material enables users $24 / 7$ access, anywhere, provided that they have access to the appropriate technology. Digitisation is also one of the measures that can assist in preventing the loss, damage and theft of historical artefacts. Fabunmi, Paris and Fabunmi (2006:23) emphasise that the major purpose of digitisation is to enhance access and improve preservation, and that a great number of the world's major collections of cultural heritage material have not yet been digitised. This study investigated the extent of digitisation of cultural heritage material in memory institutions in the Western Cape (WC) province, South Africa, and the challenges that these institutions face in digitising their collections.

The United Nations Educational, Scientific and Cultural Organization's (UNESCO) Memory of the World (MOW) programme aims to increase awareness and protection of the world's documentary heritage and achieve its universal and permanent accessibility (UNESCO 2002:6), an aim that is well serviced by digitisation. A 1999 survey by The International Federation of Libraries (IFLA) and UNESCO assessed the state of digitisation activity worldwide (Gould \& Ebdon 1999:1). The European Commission (EC) NUMERIC project aimed in 2008 to find measures for digitisation activities, especially the digitisation of national cultural heritage (Poll 2010:123, 130). The subsequent ENUMERATE surveys aimed to 'create a reliable baseline of statistical data about digitisation, digital preservation and online access to cultural heritage in Europe' (Terras 2015a:76). The fifth major study into the current state of digitisation in Europe was summarised in the 2017 Report on ENUMERATE Core Survey 4 (Nauta, Van der Heuvel \& Teunisse 2017:4). In 2005, the EC adopted a Communication 'i2010: Digital Libraries' that outlines the vision underlying the digital libraries initiative and deals with Europe's cultural heritage. These initiatives mark the creation of policies on digitisation and online accessibility of cultural heritage 
in Europe and have contributed to the development of the Europeana digital platform (European Commission [EC] 2017). Similar projects have been undertaken elsewhere: in September 2002, the Council on Library and Information Resources (CLIR) commissioned a survey of North Americanbased digital cultural heritage initiatives (DCHIs) (Zorich 2003:1), and in the USA, the Library of Congress (LC) established the American Memory Project as a digital resource for historical and cultural collections (LC n.d.a.).

Digital Innovation South Africa (DISA), encouraged by the Andrew W. Mellon Foundation, through a workshop held at the University of the Witwatersrand (Wits) in 1997, was the first collaborative national digitisation project in South Africa. It included several heritage and research stakeholders from government, tertiary institutions, libraries and archives, to make South African material of high sociopolitical interest accessible online to scholars and researchers worldwide (Pickover 2008:1). In 2009, an audit of South African digitisation initiatives (SADIs), sponsored by the Carnegie Foundation of New York, was undertaken by the National Research Foundation (NRF). According to the NRF this audit was:

... the first phase of an extensive exploration of the national development needs for effective and efficient digitisation and preservation of valuable heritage and research collections in the South African system. (Page-Shipp 2011:1)

Some of the findings and recommendations were that priority themes should be identified for digitisation projects; a National Heritage Repository and a National Digitisation and Preservation Centre Support Centre should be established; and attention should be given to infrastructure, training and skills development. Best practice guidelines were needed because of a lack of a National Policy on Digitisation (Page-Shipp 2011:9-14).

The NRF also participated in the SADI workshop at Wits in 2013. One of the aims of SADI was to 'foster co-operation in creating collections and providing online access to South African cultural and heritage resources in digital form'. There was a proposal that the NRF hosted a national digitisation and digital data preservation centre, which could also include a heritage repository (Pickover \& Mohale 2013:6). Currently, a third draft of the revised 1996 'White Paper on Arts, Culture and Heritage' is being finalised to establish an integrated national dispensation of arts, culture and heritage in South Africa (Department Arts and Culture [DAC] 2017). At a regional level, the new 'Digitisation Policy of Western Cape Governmental Bodies 2017' has been available since 2017 (Western Cape Government [WCG], Department Cultural Affairs and Sport [DCAS], Western Cape Archives and Record Service [WCARS] 2017.

Cultural heritage is the legacy of physical artefacts and intangible attributes of a group or society that are inherited from past generations, maintained in the present and bestowed for the benefit of future generations' (UNESCO 2016b) and is commonly divided into two categories: tangible and intangible. Tangible cultural memory includes 'prints (books, journals and newspapers), photographs, museum objects, archival documents, sound and audio materials, monuments and archaeological sites' (Chowdhury 2015:1-2). Intangible cultural heritage is defined as:

... the practices, representations, expressions, knowledge, skills as well as the instruments, objects, artefacts and cultural spaces associated therewith - that communities, groups and in some cases, individuals recognise as part of their cultural heritage. (UNESCO 2002:4, 2003a:4)

Cultural heritage can be represented in three different digital forms: born digital, digitised heritage and the digital information about heritage such as descriptions (DAC 2010:7). The DAC drafted a national policy on the 'Digitisation of Heritage Resources', of which the final draft for public review dated August 2010 (DAC 2010:17) described its scope as directed towards the digitisation of heritage resources for preservation, access and management of ownership.

The United Nations Educational, Scientific and Cultural Organization supports Open Access (OA), 'the online availability of scholarly information to everyone, free of most licensing and copyright barriers - for the benefit of global knowledge flow, innovation and socio-economic development' (UNESCO 2016a). According to Terras (2015b:344), OA encourages the availability of digitised cultural heritage content for use and reuse, in line with the position that cultural heritage institutions should make public domain material, digitised with public funding, as widely available as possible for access and reuse and governments should support it for the long-term provision of cultural memory (Evens \& Hauttekeete 2011:164). Open Access, however, brings other challenges such as intellectual property, copyright and funding issues to cultural heritage collections. The tension between access to digital heritage materials being 'free of unreasonable restrictions' (UNESCO 2003b:2) and the protection of sensitive and personal information 'from any form of intrusion' (UNESCO 2003b:2) is not negligible and requires discretion and careful management that extends beyond the mere instrumentation of digitisation. Britz and Lor (2004:216) report that access to and preservation of Africa's digitised collections of documentary heritage may be problematic in the long run because of technological, economic, political, legal and moral reasons. Open Access to digitised material in South African Archives collections is also limited (Archival Platform 2015:102, 145). South Africa, a developing country, is following the digitisation trend set by developed countries (Liebetrau \& Mitchell 2010:2), and according to Peters et al. (2015:204), 'the digitisation of cultural heritage was embraced by the heritage sector in South Africa'. However, while Sula (2015:26) has recommended that cultural heritage institutions should digitise material as quickly as possible, according to Peters et al. (2015:204), this poses particular challenges in the developing world. The 'Executive Summary' of the 2014 State of the Archives report states that 'the huge potential of digitisation in support of preservation and public access has not been harnessed' (Archival Platform 2015:5). 
Memory institutions (typically grouped as libraries, archives and museums [LAM]) are important custodians of the past and contribute to the management of our national cultural heritage for use and reuse of digitised material (Terras 2015b:738). In South Africa, 'an increasing number of cultural heritage institutions have already embarked on digitisation as a means of preservation and improving access to their collections', according to Sithole (2006), as cited by Chisa and Hoskins (2015:56).

There are many issues that concurrently impact on cultural heritage in South Africa, of which digitisation represents only a small subset. The boundaries of this study did not allow for an extensive exploration of all these issues or where they may intersect with the findings of this study, and it should be noted that some of the challenges raised may be factors or symptoms of these broader systemic challenges. This study investigated the current status of digitisation of cultural heritage material in memory institutions in the WC, South Africa. Similar studies have been conducted worldwide but the listing of digitised cultural heritage collections has not been updated in the WC since the 2009 NRF audit. The challenges that institutions face during the processes of digitisation, which impact on the delivery of the required or planned digitised material for cultural heritage collections, were also investigated. The analysis was carried out against the background of global and national initiatives: programmes, projects, policies and acts advancing the digitisation and preservation of cultural heritage collections.

\section{Literature review}

The theory used in this study, the theory of constraints (TOC), a systematic management approach, was developed by Eli Goldratt. Theory of constraints 'focuses on understanding and managing the constraints that stand between an organisation and the attainment of its goals' (McNair 1999:1). Krajewski, Ritzman and Malhatra (2013:266) state that the practical application of the TOC involves identification of the bottleneck(s), constraints or challenges as a first step. The identification of challenges can assist institutions in striving to find solutions by creating or implementing programmes or policies successfully used in other institutions, nationally or internationally. Assuming a common goal of cultural heritage institutions to be preservation of and access to cultural heritage through digitisation, challenges to digitisation were identified in the literature and applied as a lens through which to examine the constraints faced by these institutions. Ruthven and Chowdhury (2015:xv) identified a range of challenges in the digitisation of cultural heritage, some associated with 'tools and technologies', while others relate to 'access and use'. Physical constraints can arise from poor technological infrastructure, while non-physical constraints may include lack of policy or staff expertise. Liebetrau and Mitchell (2010:2) enumerate the challenges as 'expertise; human and financial resources; technology infrastructure; adoption of standards; creation of guidelines and the implementation of policies', each of which is explored in more detail below.

\section{Expertise and human resources}

The 2009 NRF audit identified 'the development and maintenance of knowledge and skills for digitisation and the training and retention of skilled people' (Page-Shipp 2011:37) as a challenge. The lack of staff expertise to oversee a digitisation project and the need for appropriate skills training or development, which creates further financial challenges, is raised by many authors, including Angevaare (2009:5), Asogwa (2011) and Brown (2013:4, 106).

\section{Financial resources}

The 2009 NRF audit (Page-Shipp 2011:37) mentions 'a lack of resources relating to finance and technology infrastructure (software, hardware and systems) and connectivity' as a challenge. Digitisation projects are expensive and the cost of staff training must be considered along with technical infrastructure. 'A well-funded digitization project assures new and improved services and sustainability of the project' (Asogwa 2011). Financial sustainability and funding are a common concern of all digitisation projects (Breeding 2014:17).

\section{Technology infrastructure}

The DigiCULT report (EC 2002) finds that the most pressing issues and challenges for access and use are 'sustainability of e-services, technical interoperability, threat of a technology gap, and human capital'. It also mentions that standards must be developed to assist with searches for access and that staff must be skilled to use the new technologies. According to Asogwa (2011), digital information is at risk of loss through technological obsolescence. He also states that 'most African states are still lagging behind in technological and telecommunications infrastructure'. Rapid information technology changes and upgrades cause similar problems, such as 'obsolescence of formats, hardware and software issues and the lack of technical know-how' (Brown 2013:202-203).

\section{Adoption of standards}

Several digitisation standards and best practice guidelines exist, such as those for metadata (Dublin Core and Taxonomy and Naming) (Franks 2013:136, 272). Technology standards exist for image format standards (TIFF, JPEG and GIF), audio formats, digital video formats and 3D formats. The choice of standards and use of metadata is important for access to heritage material. 'From a technical standpoint ... the failure to use standard formats and media acts as an obstacle to international interoperability and the creation of networked resources' (Ministerial Network for Valorising Activities in Digitisation [MINERVA] 2003:50).

\section{Creation of guidelines}

Guidelines are needed for the selection of material for digital collections (Gould \& Ebdon 1999:13). According to Pickover (2008:194), the selection of material (content) to be digitised is important. UNESCO/PERSIST (2016:12) concludes that 'developing and implementing selection 
criteria and collecting policies is the first step to ensuring that vital heritage material is preserved for the benefit of current and future generations'.

\section{Implementation of policies}

Policies are needed to protect South Africa's archival resources. The final draft of the national policy on 'Digitisation of Heritage Resources' has been available for public review since August 2010 (DAC 2010), but has yet to be formally promulgated. The absence of a national policy means that there is no consistent local guidance to ensure appropriate standards and systems in digitising material (Archival Platform 2015:66, 104). The 2009 NRF audit report (Page-Shipp 2011:37) includes challenges such as 'policies on intellectual property rights, ownership, access licensing and prioritisation' and notes that there was no national long-term preservation strategy at the time. Pickover (2008:195) comments: 'Ultimately, it is these larger political, technical and intellectual challenges of national policies and processes around heritage' that need attention. Legal concerns, such as related intellectual property rights, are experienced as major obstacles to digitisation projects by many institutions (Evens \& Hauttekeete 2011:159; LC n.d.b.).

Challenges can slow the rate of digitisation of cultural heritage material in South Africa. However, challenges can be identified and addressed, and steps taken to handle digitisation projects more sustainably and successfully.

\section{Research methods and design}

The objective of the study was to ascertain the current state of digitisation of the cultural heritage collection(s) of the institutions in question and to find out more about their collections and digitisation procedures and policies. Secondly, it aimed to ascertain the current challenges to the digitisation of cultural heritage material in memory institutions in the WC, South Africa, with the ultimate objective of contextualising these challenges in the broader cultural heritage digitisation landscape and creating the opportunity to address the identified challenges with rigour. In this study, a quantitative research approach employed an online survey in its research design. This study is a cross-sectional study in which the data were collected over two consecutive months in 2017. The population for this study was memory institutions in the WC, South Africa. Sources used to identify the population include lists on the SA Libraries page on the Library and Information Association of South Africa website (SA Libraries n.d.), the Cape Higher Education Consortium (CHEC) website (CHEC 2015), the WC Government website (Western Cape Government [WCG], Department Cultural Affairs and Sport [DCAS] 2017) and the guide to municipalities in South Africa (Main 2017).

Judgemental sampling was used in this study: a census of the total population in the scope of this study, rather than a representative sample that could be used for extrapolation to a wider population (Babbie 2010:224-225). The WC is divided into one metropolitan municipality, the City of Cape Town Metropolitan Municipality, and five district municipalities.
This sample includes only the memory institutions in the City of Cape Town Metropolitan Municipality and the Cape Winelands District Municipality. The Cape Winelands District Municipality includes the Breede Valley Local, the Drakenstein Local, the Langeberg Local, the Stellenbosch Local and the Witzenberg Local Municipality (Municipalities of South Africa between 2012 and 2017). The memory institutions included in this sample of 28 are represented by a national library, a provincial archive, a church archive, a special library, a public library, four academic libraries and 19 museums.

Research Electronic Data Capture (REDCap) was used as a tool for building the self-administered online questionnaire, a link to which was emailed to respondents. The questionnaire was designed by the researcher, and based on the 1999 IFLA/UNESCO survey of digitisation and preservation (Gould \& Ebdon 1999), the ENUMERATE project performed in Europe (Stroeker \& Vogels 2014) and the 2009 NRF audit of digitisation initiatives in South Africa (Page-Shipp 2011). The challenges for digitisation constraints identified in the literature review were used as a guideline to generate and formulate the 19 research questions. Ethical clearance and permission were received from the relevant organisations and memory institutions. Steps were followed in the research design and processes to ensure the quality of the data, which was collected with REDCap. Descriptive statistics were used to summarise data and tables and graphs were used to communicate the research findings.

\section{Ethical consideration}

The Ethics Review Committee of the Library and Information Studies Centre on behalf of the Humanities Faculty of the University of Cape Town provided ethical clearance to conduct this study (Ethical Clearance Number: UCTLIS201705-02). As indicated in the manuscript, the study and associated instruments were received and approved by the Library and Information Studies Centre (LISC) Research \& Ethics Committee on behalf of the UCT Faculty of Humanities. Permission to conduct the research with relevant staff members was sought and obtained from all responding institutions, with assurance of anonymity. Plagiarism has been avoided and all references and assertions have been carefully and rigorously checked.

\section{Results and discussion}

Twenty-eight invitation letters were sent to identified institutions. One institution declined to participate because knowledge of digitisation was lacking. The link to the online questionnaire was sent to 27 memory institutions. At some institutions, there was more than one participant, or more than one type of digitised collection, in which case a different questionnaire was completed for each collection.

Seventeen online questionnaires were successfully completed and returned, providing a response rate of $63 \%$. The 14 institutions were represented by seven libraries (four academic, one national, one public and one special), two archives 
and five museums. Data were primarily organised by type of collection rather than by institution type. The 17 collections analysed comprised seven archival, six library and four museum collections.

\section{Digitisation activity}

\section{Engagement in and state of digitisation activities}

Sixteen $(94 \%)$ of the 17 respondents were engaged in some sort of digitisation activity, the exception being a museum. Of the collections identified for digitisation, only one was intended to be fully digitised.

\section{Digitisation approaches}

Respondents were asked whether cultural heritage digitisation was performed on the premises, outsourced, or a combination of the two, and if they acted as a digitisation service provider. Multiple responses were allowed. Nine respondents (53\%) use a hybrid of in-house and outsourced digitisation and eight $(47 \%)$ undertake their own digitisation activities exclusively. One institution indicated that they also acted as a digitisation service provider to other memory institution(s).

A summary of the state of digitisation activity is presented in Figure 1. It is worth noting that more than half of the respondents $(59 \%)$ in this study indicated that they have identified less than $40 \%$ of their analogue or physical cultural heritage collection(s) for possible digitisation, with no collections fully digitised to date. The majority of collections (59\%) identified for possible digitisation have not yet had 20\% of their content digitised and digitisation of three collections $(18 \%)$ has not yet begun. Four $(24 \%)$ of the respondents indicated that they are not currently engaged with any digitisation projects at this stage. The sample is too small to draw any conclusions about these reported percentages, but in comparison, Nauta et al. (2017:6) stated that '22\% of the analogue collection [in European cultural heritage institutions] is on average currently digitised and $54 \%$ still needs to be digitised'. The DigiCULT report (EC 2002:40) stated that 'in the
Information Society, ... only the digital will survive in the memory of a nation as it is more readily available and accessible than analogue cultural heritage resources'. If the situation in the institutions surveyed is representative of the broader state of digitisation in LAMs in South Africa, this constitutes an alarming backlog if the objectives of cultural heritage digitisation in the country are to be met.

\section{Collection resource types}

The questionnaire allowed for the identification of nine types of text-based and 11 types of visual or graphic resources for digitisation in collections. Multiple responses were allowed.

\section{Text resources}

Manuscripts (handwritten books) are the most popular targets $(18 \%)$, followed by newspapers $(14 \%)$, diaries $(13 \%)$, letters $(10 \%)$, journals $(9 \%)$ and microfilm $(8 \%)$. While libraries favour newspapers and manuscripts for digitisation of textual resources, in archival collections it was manuscripts and in museum collections both manuscripts and diaries (Figure 2).

\section{Visual or graphic resources}

Photographs emerged as the most popular of the visual or graphic resources for digitisation (14 respondents), followed by maps (10), sound recordings (8), drawings (7) and paintings and slides (6 each). In library collections, there was an equal proportion of maps and photographs; in the archival collections, photographs were the most popular, followed by maps and sound recordings; in the museum collections, photographs and slides were the most frequently targeted (Figure 3).

The wide variety of types of material targeted for digitisation raises questions of standards for formats and for metadata, as well as the skills and infrastructure burdens that different types of resources require for digitisation. The emphasis on manuscripts and newspapers across the memory institution types indicates a strong sense of the historic and cultural value

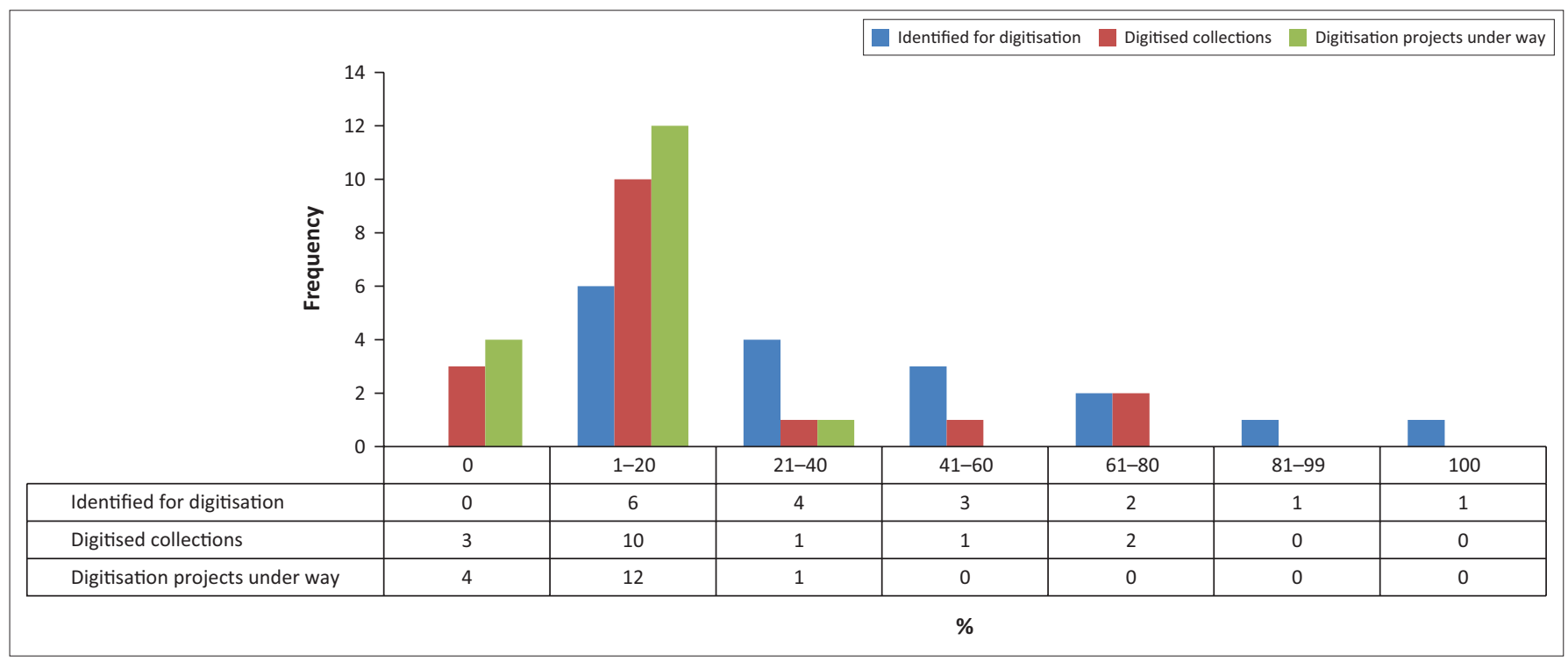

FIGURE 1: Summary of digitisation activity $(N=17)$. 


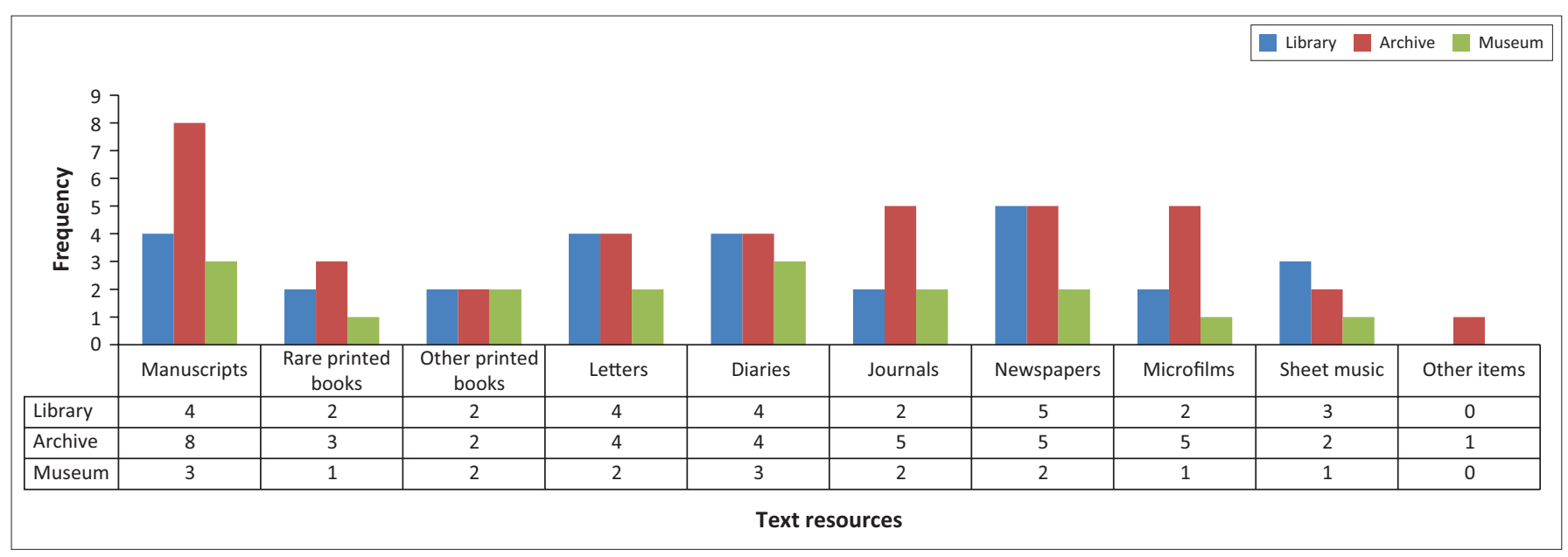

FIGURE 2: Type of text resources in libraries, archives and museums $(N=17)$.

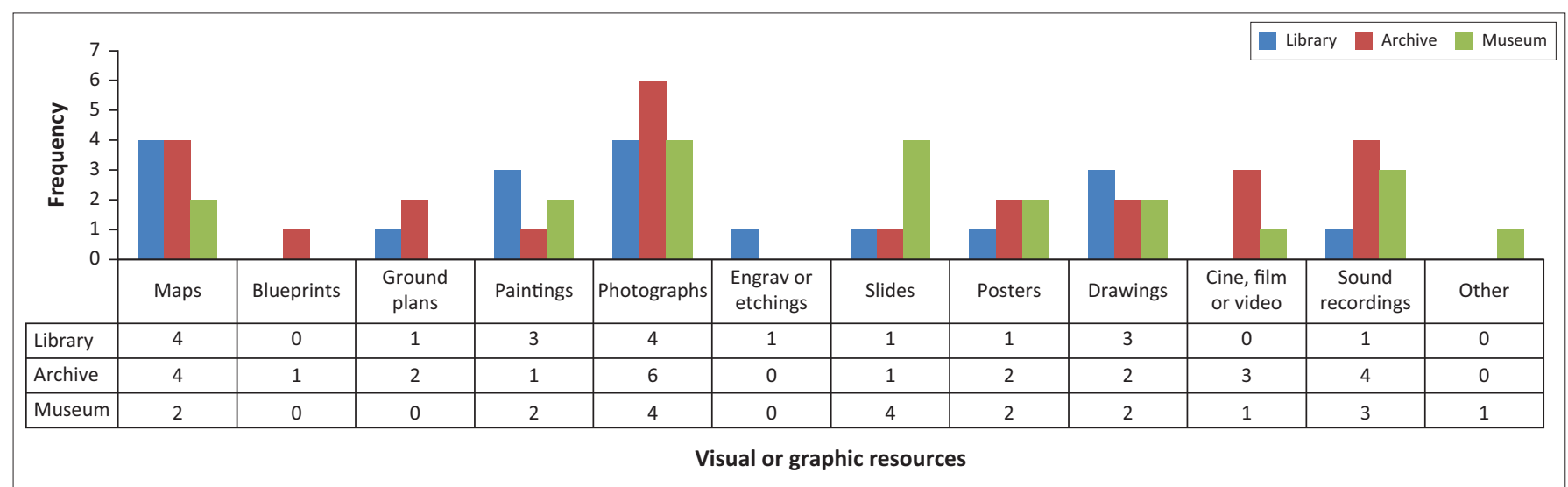

FIGURE 3: Type of visual or graphic and other resources in libraries, archives and museums $(N=17)$.

of these items, although not necessarily their rarity. While manuscripts are typically one of a kind, there is a risk of duplication of effort in digitising newspapers, multiple exemplars of which may exist in various places and formats and may already be digitised and available online. The relative preference for text-based resources $(56 \%)$ over visual or graphic resources (44\%) may be attributable to the perceived relative ease of digitising text and storing digitised text, although this speculation is open to debate. Photographs (22\%) were the most popular visual or graphic resources group targeted for digitisation, followed by maps (15\%), across all the collections. This study did not investigate specific digitisation strategies for these resources in any depth, but it would be interesting to know to what extent digitisation of maps is directly linked to externally available data, such as global information systems (GIS), which would add significant value to the digitisation effort.

\section{Policies, strategies and procedures}

A well-planned digitisation strategy is needed for an institution to deliver a valuable and sustainable contribution to the digitisation of cultural heritage. Good management of digitisation should include guidelines for digitisation, collection management, access, metadata, intellectual property (including copyright and privacy issues) and how digitisation and preservation should be performed as recommended by digitisation policies (Anderson 2006:21). The study investigated selection criteria, policies, strategies and procedures and standards applied to digitisation projects in the population. Using the literature as a framework for the question, respondents were asked to describe criteria for and purpose of the selection of material for digitisation, as shown in Figure 4. Multiple responses were allowed. Fifteen respondents considered improved access and preservation to be equally important criteria, and 10 respondents prioritised reduction of risk of damage to material by handling.

The existence at the LAMs of written standards or best practices, strategies or policies was ascertained regarding digitisation, preservation, collection development, selection for digitisation, intellectual property, metadata, records management and content management. Multiple responses were allowed. Nine respondents confirmed the existence in their institutions of standards or best practices for both records management and preservation, and eight for digitisation and metadata. Nine have specific strategies for records management and eight for collection development. Eleven respondents followed collection policies. Policies were used by seven respondents for records management, by six for intellectual property, by four for preservation and by three for digitisation. None of the respondents indicated that they have implemented policies for metadata. 
The use of guidelines largely reflects the key activities and priorities of the various institution types: libraries, whose traditional concern is cataloguing, have implemented standards for metadata, preservation and content management, but their main concern was policies for collection development activities, while archival collections, for whom provenance is a primary concern, focused on records management guidelines. Museums showed the highest use of guidelines for collection development, followed by preservation.

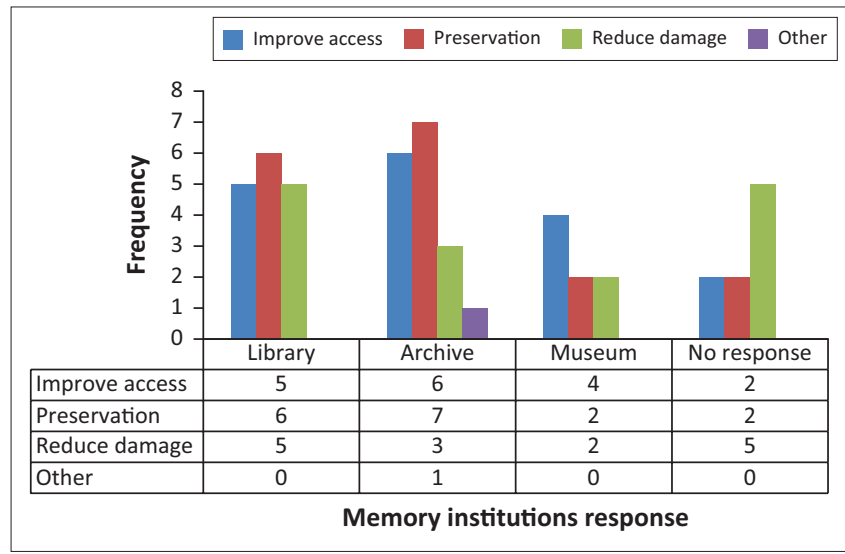

FIGURE 4: Selection criteria in libraries, archives and museums $(N=17)$.

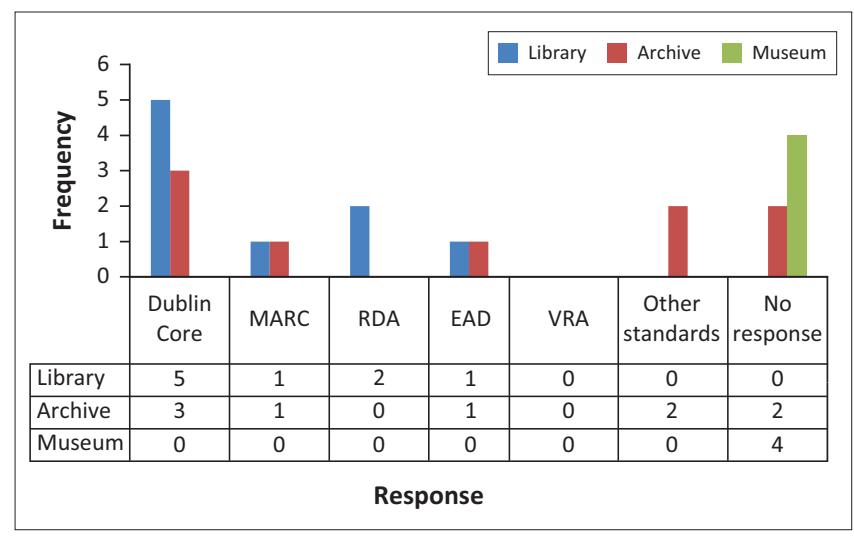

MARC, Machine-Readable Cataloguing; RDS, Resource Description and Access; EAD, Encoded Archival Description; VRA, Visual Resources Association.

FIGURE 5: Metadata standards $(N=17)$.
The draft policy on the 'Digitisation of Heritage Resources' (DAC 2010:56) stated that ' $n$ ] ational metadata and vocabulary standards must be adopted to ensure semantic interoperability between digital collections' and metadata guidelines are necessary for description, retrieval and discovery of digital content (Liebetrau 2010:30). The use of metadata standards for retrieval, access and use in the population was ascertained (multiple responses allowed). Dublin Core was used by $47 \%$ of respondents and Machine-Readable Cataloguing (MARC), Resource Description and Access (RDA), Encoded Archival Description (EAD) and 'Other' types of metadata used were all implemented equally by two respondents each. One respondent commented: 'Locally we comply with the National Automated Archival Information Retrieval System (NAAIRS), however AToM was also explored and partially adopted'. Figure 5 shows the metadata standards used per collection by LAM type. Most of the libraries were following international metadata standards. While $47 \%$ of respondents reported the existence of internal standards for metadata, there were no metadata policies evident in any of the institutions. Libraries reported high compliance with metadata standards archives and museums.

The levels of standards used during the digitisation of cultural heritage material were international, national, domain-specific or local in-house. Multiple responses were allowed. The results in Figure 6 show that the 'local in-house' standards predominate $(65 \%)$, followed by international standards (53\%).

The development and implementation of 'selection criteria and collecting policies is the first step to ensuring that vital heritage material is preserved for the benefit of current and future generations' (UNESCO/PERSIST 2016:11). It is important for LAMs to target the correct types of cultural heritage material for digitisation by including digital collection development in the collection development policy of their institution. While more than half of the respondents $(65 \%)$ indicated that they followed 'collection development policies', it is not clear if this included specific digital collection development. The criteria guiding the selection of material for digitisation indicated by 15 respondents showed

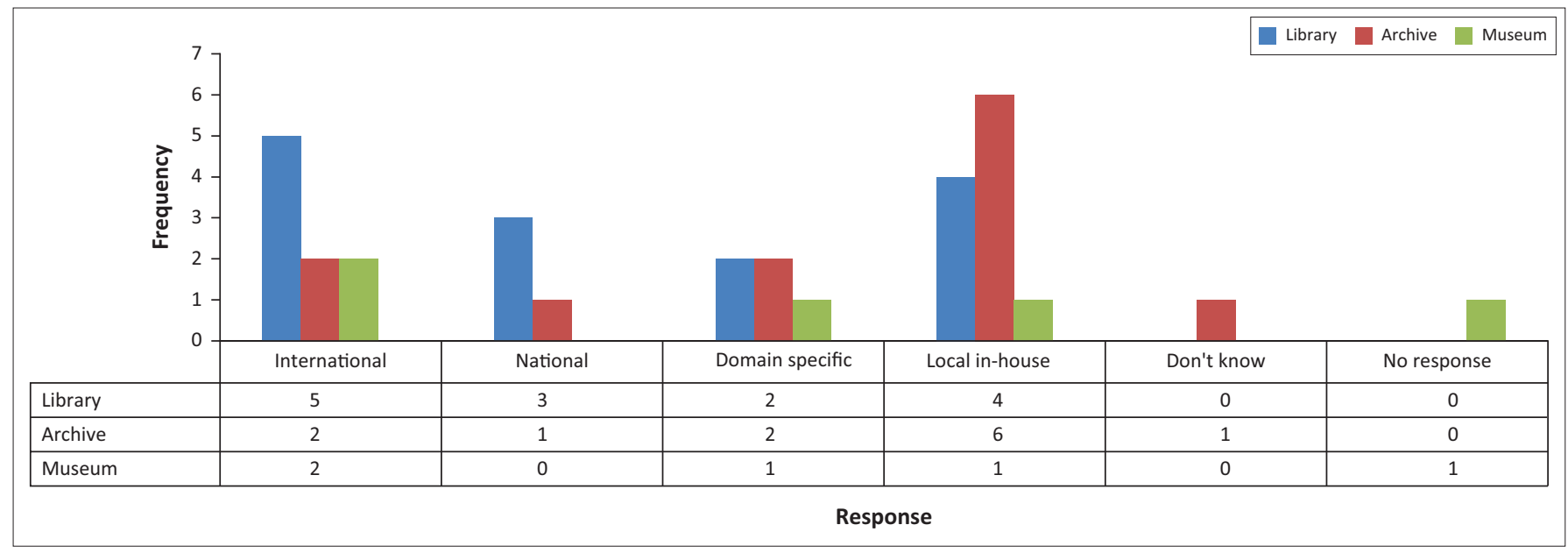

FIGURE 6: Level of standards $(N=17)$. 


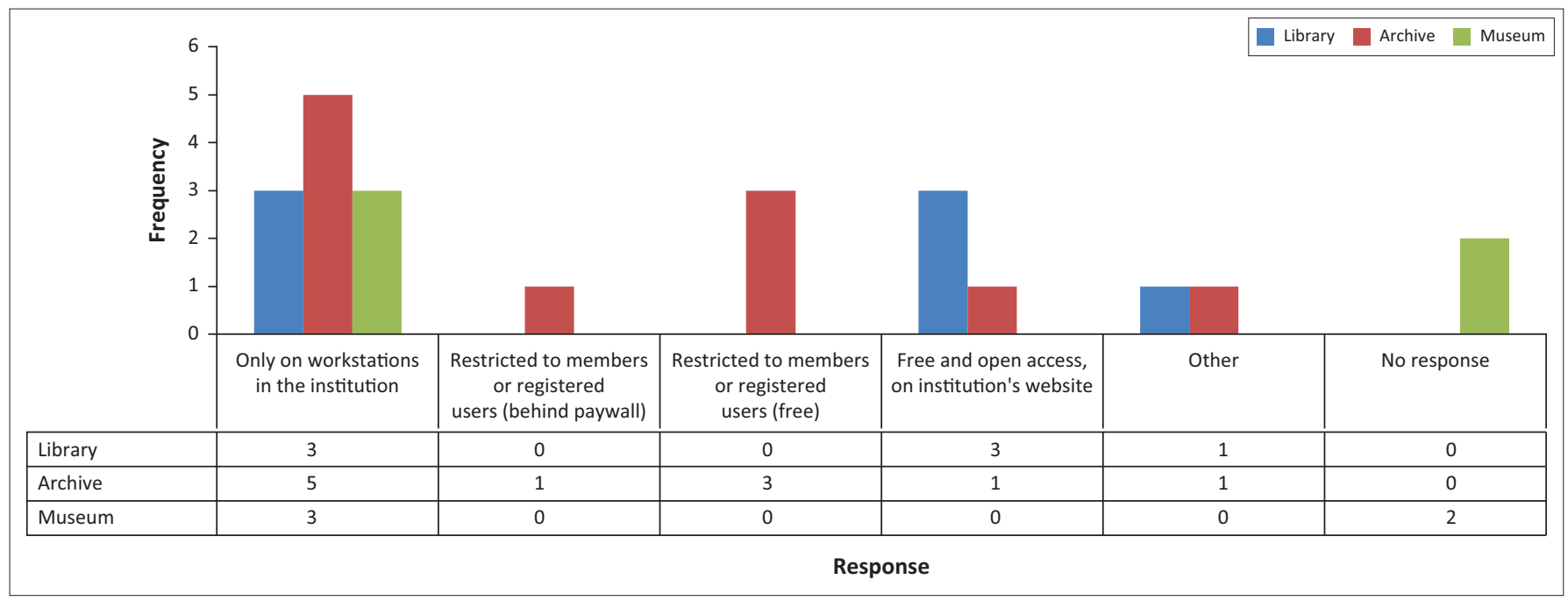

FIGURE 7: Manner of access $(N=17)$.

that improved access to the collection ( $88 \%$ ) and preservation $(88 \%)$ were equally important for the institutions surveyed.

\section{Access to the collection}

Gould and Ebdon (1999:26) state that 'any library collection is only as good as the access that is provided to that collection'. A small proportion of the respondents $(29 \%)$ had policies that set conditions for access to the digitised collections. Figure 7 shows manners of access. Most of the respondents (65\%) indicated that their only institutions provide access to their digitised collections on internal workstations. That was mostly the case in access to archival collections. Twenty-four per cent of respondents' institutions provide 'free and $\mathrm{OA}$ on the institution's website', followed by $18 \%$ who provided access free of charge, but restricted to members or registered users.

\section{Challenges to digitisation}

Finally, the challenges to digitisation of cultural heritage material experienced in the institutions in question were identified and the extent of management's involvement in these challenges rated by participants on a scale of 'Don't know/Not aware' to 'Formally recognised by management, with plans to address these challenges'.

\section{Expertise}

On average, $76 \%$ of the respondents acknowledged the limited technical skills of staff and the lack of training as a challenge, while $70 \%$ indicated that the limited knowledge had an impact on digitisation activities.

\section{Human and financial resources}

The low number of personnel dedicated to digitisation activities was seen as a challenge in $82 \%$ of the replies. The limited availability of skills in the marketplace needed for digitisation was recorded by more than half (53\%) of the respondents, while lack of funding was identified by $70 \%$ of the respondents. Funding is a common concern of all digitisation projects (Breeding 2014:17). Funding for sustainability remains a challenge in the current economic climate and digitisation is an expensive exercise (PageShipp 2011:30). It is a challenge for institutions and the government to support the financing of digital projects, but policies should be in place to control local and foreign funding to prevent loss of ownership of cultural heritage material (DAC 2010:43 \& 51).

\section{Technology infrastructure}

Fifty-three of the respondents experienced network bandwidth or slow Internet as a problem and $76 \%$ identified equipment (hardware) as an obstacle. Internet speed and access have been improving in South Africa, but the country remains behind global standards and is ranked '92nd out of 176 countries in the International Communication Union's 2017 ICT Development Index' (Gillwald, Onkokame \& Rademan 2018:18). The WC Government has invested heavily in broadband and there is continuous improvement in service delivery, but it is still costly (Western Cape Government [WCG] 2017). 'Users must also be able to access and use digital information' and 'the development of Intercommunication Technology capacity should be supported and funded' (DAC 2010:48). The digital divide should be managed to enable all citizens to have access to cultural heritage information. Digitisation equipment is expensive and highly skilled technical staff is required to produce digital images of quality (Mcllwaine 2002:9). Technology, a key enabler of digitisation, can also be a constraint and if identified by the TOC as the weakest link, it must be strengthened (McNair 1999:2).

\section{Standards, guidelines and policies}

The 2009 NRF audit report mentions that a lack of standardisation is often raised as a concern in the digitisation field: 'Standardisation is important for the sake of discovery of the digitised objects on the web; the reusability of objects, to minimise repeat work; and the interoperability of systems' (Page-Shipp 2011:23). Inconsistent application of standards and the lack of institutional guidelines and policies were identified by $53 \%$ of the respondents. The poor implementation of policies, in general, intellectual property 
and privacy issues, as well as the burden of legal compliance, were indicated by $41 \%$ of the respondents. Intellectual property (copyright) and privacy issues have not been investigated in depth. Ownership and cultural sensitivity issues related to specific indigenous communities are important when considering digitisation of cultural heritage material to prevent exploitation or financial loss (Chowdhury 2015:38; Page-Shipp 2011:5, 39). The 'Digitisation Policy' Western Cape Government [WCG], Department Cultural Affairs and Sport [DCAS], Western Cape Archives and Record Service [WCARS] 2017:11) states that 'due to the rapid evolution of technology and a variety of industry standards, the WCARS does [sic] not prescribe to a specific technical standard' but does advise adherence to international standards. Nauta et al. (2017:5-6) state in the ENUMERATE Core Survey 4 that ' $42 \%$ of the institutions had a digital strategy and $27 \%$ of institutions had a written digital preservation strategy that is endorsed by management'.

\section{Management}

Forty-one per cent of the respondents acknowledged that the management of digitisation of cultural heritage material is a challenge. Good planning and management are needed for any cultural heritage material digitisation project. Management must acknowledge the challenges encountered during digitisation projects to ensure effective and efficient digitisation of cultural heritage material by striving to minimise or eliminate constraints (Krajewski et al. 2013:265). Constraints that are managed well can lead an organisation to improve its performance and fulfil its goals.

\section{Conclusion}

Challenges that memory institutions must manage during digitisation of cultural heritage material were identified. Based on the discussion of the main findings, the following conclusions may be drawn:

- The digitisation of cultural heritage material is generally embraced by memory institutions in the WC, especially by libraries and in archival collections. A low response rate from museums could be an indication of lack of knowledge or a lack of digitisation initiatives in smaller museums.

- A wide variety of analogue or physical, text-based, graphic and visual cultural heritage material has been identified for digitisation.

- Only a draft 'National Policy on Digitisation' (DAC 2010) is available, but a 'Digitisation Policy of Western Cape Governmental Bodies 2017' (WCG et al. 2017) exists. Memory institutions in the WC are following professional guidelines or international guidelines, but there is no fixed national policy, guidelines or standards on digitisation, which could hamper interoperability and access.

- While OA is preferable for digitised cultural heritage material, access is still limited in and by most memory institutions.
- The digitisation challenges experienced in memory institutions globally are also experienced in the WC but vary in intensity between institutions. Staff expertise in digitisation is a concern in most institutions, specifically in respect of limited knowledge, limited technical skills and lack of training. In the WC, the provision of Internet connectivity is not as much of a problem as elsewhere in Africa.

Enhancing 'records management structures and systems and promoting access to information' is one of the mission statements of the South African 'White Paper on Arts, Culture and Heritage' (DAC 2017:8). The digitisation of cultural heritage should be supported, and efforts of memory institutions should be strengthened by limiting or eliminating challenges in support of the United Nations 2030 Agenda for Sustainable Development. Governments are called upon 'to strengthen efforts to protect and safeguard the world's cultural and natural heritage (target 11.4) as well as to ensure public access to information and protect fundamental freedoms' (UNESCO 2015). We believe that the outcomes of this research will contribute to increased effectiveness of cultural heritage digitisation in the WC and may have wider applications for further planning and policy considerations for digitisation in memory institutions. Opportunities for access to digital information are plentiful, so the challenges that come with digitisation should be addressed through knowledge of the constraints and how to manage them.

\section{Recommendations}

The study was limited to the WC with a small, nonprobability sample; therefore, the results could not be generalised to the rest of South Africa. As few comments were provided by the respondents, the data acquired were not as rich as was expected. However, it will probably provide impetus for in-depth discussion of the challenges faced in the digitisation of cultural heritage material. A repeat of the 2009 NRF audit of the SADI would be valuable in assessing the broader scope of the current state of digitisation in South Africa.

\section{Acknowledgements}

The authors acknowledge the time and participation of the participants in the research.

\section{Competing interests}

The authors declare that they have no financial or personal relationships that may have inappropriately influenced them in writing this article.

\section{Authors' contributions}

B.d.1.P. undertook the study as a Master of Library and Information Studies; the dissertation was submitted to the Faculty of Humanities, University of Cape Town, with R.H. as 
her research supervisor. B.d.l.P.'s role included identifying the topic; designing, validating and administering the questionnaire data collection instrument; and performing data analyses for the purposes of the dissertation, with guidance from R.H. R.H. reviewed several drafts of the dissertation and gave direction to prepare the article for journal publication.

\section{Funding information}

This research received no specific grant from any funding agency in the public, commercial or non-profit sectors.

\section{Data availability statement}

Data are available for sharing.

\section{Disclaimer}

The views and opinions expressed in this article are those of the authors and do not necessarily reflect the official policy or position of any affiliated agency of the authors.

\section{References}

Anderson, C.G., 2006, Ethical decision making for digital libraries, Chandos Publishing, Oxford.

Angevaare, I., 2009 "Taking care of digital collections and data: "Curation" and organisational choices for research libraries', Liber Quarterly 19(1), 1-12, viewed 21 May 2016, from http://liber.library.uu.nl/.URN:NBN:NL:Ul:10-1-113552.

Archival Platform, 2015, State of the archives: An analysis of South Africa's national archives system, 2014 Report, The Archival Platform, University of Cape Town, Rondebosch, South Africa, viewed 10 March 2016, from http://pmg-assets.s3website-eu-west-1.amazonaws.com/150901archives.pdf.

Asogwa, B.E., 2011, 'Digitization of archival collections in Africa for scholarly communication: Issues, strategies, and challenges', Library Philosophy and Practice, viewed 11 April 2016, from http://digitalcommons.unl.edu/libphilprac/651.

Babbie, E., 2010, The practice of social research, Wadsworth, Belmont, CA.

Breeding, M., 2014, 'Ongoing challenges in digitization', Computers in Libraries 34(9), 16-18.

Brown, A., 2013, Practical digital preservation: A how-to guide for organizations of any size, Facet Publishing, London.

Britz, J. \& Lor, P., 2004, 'A moral reflection on the digitization of Africa's documentary heritage', IFLA Journal 30(3), 216-223. https://doi.org/10.1177/034003520403 000304

Cape Higher Education Consortium (CHEC), 2015, viewed 10 October 2016, from http://www.chec.ac.za/index.html.

Chisa, K. \& Hoskins, R., 2015, 'Decolonising indigenous intellectual and cultural rights in heritage institutions: A survey of policy and protocol in South Africa', Mousaion 33(3), 55-72.

Chowdhury, G.G., 2015, 'Management of cultural heritage information: Policies and practices' in I. Ruthven \& G.G. Chowdhury, (eds.), Cultural heritage information: Access and management, pp.37-62, Facet Publishing, Croydon.

Department Arts and Culture (DAC), 2010, National Policy on the digitisation of heritage resources, Final draft for public review August 2010, v8, viewed 10 March 2016, from http://www.archivalplatform.org/images/resources/ NATIONAL_POLICY_ON_DIGITISATION_V8.pdf.

Department Arts and Culture (DAC), 2017, Revised White paper on Arts, Culture and Heritage, Third draft, February 2017, For discussion only, viewed 26 August 2017 from http://www.dac.gov.za/sites/default/files/Legislations\%20Files/Revised\%20 3rd\%20Draft \%20RWP\%20on\%20ACH\%2OFEBRUARY\%202017.pdf.

European Commission (EC), 2002, Directorate-General for the Information Society, 2002, The DigiCULT report: Technological landscapes for tomorrow's cultura economy; unlocking the value of cultural heritage: Full report, viewed 07 November 2017, from http://www.digicult.info/pages/report2002/dc_fullreport_230602 screen.pdf.

European Commission (EC), 2017, Europeana - a European cultural heritage platform for all, viewed 15 January 2018, from https://ec.europa.eu/digital-single-market/ en/europeana-european-digital-library-all.

Evens, T. \& Hauttekeete, L., 2011, 'Challenges of digital preservation for cultural heritage institutions', Journal of Librarianship and Information Science 43(3), 157-165. https://doi.org/10.1177/0961000611410585

Fabunmi, B.A., Paris, M. \& Fabunmi, M., 2006, 'Digitization of library resources: Challenges and implications for policy and planning', International Journal of African \& African American Studies 5(2), 23-36.
Franks, P.C., 2013, Records and information management, Facet Publishing, London.

Gillwald, A., Onkokame, M. \& Rademan, B., 2018, The state of ICT in South Africa, viewed 20 April 2019, from https://researchictafrica.net/wp/wp-content/uploads/2018/10/ after-access-south-africa-state-of-ict-2017-south-africa-report_04.pdf.

Gould, S. \& Ebdon, R. (eds.), 1999, IFLA/UNESCO survey on digitisation and preservation, IFLA offices for the UAP and Interlending, Boston Spa.

Krajewski, L.J., Ritzman, L.P. \& Malhatra, M.K., 2013, Operation management processes and supply chains, Pearson Education Limited, Harlow.

Library of Congress (LC), n.d.a., American Memory, viewed 10 March 2016, from https://memory.loc.gov/ammem/index.html.

Library of Congress (LC), n.d.b., Challenges to building an effective digital library viewed 10 June 2016, from http://memory.loc.gov/ammem/dli2/html/cbedl. html.

Liebetrau, P., 2010, 'Metadata', in P. Liebetrau \& J. Mitchell (eds.), Managing digital collections: A collaborative initiative on the South African Framework, pp. 30-34

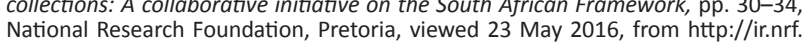
National Research Foundation, Pretoria, viewed 23 May 2016, from http://ir.nrf.
ac.za/bitstream/handle/10907/87/002 mandig2010.pdf? sequence=1\&is Allowed $=y$.

Liebetrau, P. \& Mitchell, J. (eds.), 2010, Managing digital collections: A collaborative initiative on the South African Framework, National Research Foundation, Pretoria, viewed 23 May 2016, from http://ir.nrf.ac.za/bitstream/handle/10907/ 87/002 mandig2010. pdf?sequence=1\&isAllowed $=y$.

Main, O., 2017, The local government handbook: South Africa 2017: A complete guide to municipalities in South Africa, Yes! Media, Cape Town, viewed 22 September 2017, from https://municipalities.co.za/.

Mcllwaine, J., 2002, Guidelines for digitization projects for collections and holdings in the public domain, particularly those held by libraries and archives. International Federation of Library Associations and Institutions (IFLA), The Hague, viewed 18 December 2017, from https://www.ifla.org/files/assets/ preservation-and-conservation/publications/digitization-projects-guidelines. pdf.

McNair, C.J., 1999, Theory of Constraints (TOC) management system fundamentals. Institute of Management Accountants (IMA), Montvale, NJ, viewed 28 August 2016, from https://www.imanet.org.cn/uploads/resource/2015-11/14470604145309.pdf.

Ministerial Network for Valorising Activities in Digitisation (MINERVA), 2003, Best practice handbook, viewed 10 June 2016, from http://www.minervaeurope. org/structure/workinggroups/goodpract/document/bestpracticehandbookv 1.1.pdf.

Nauta, G-J., Van der Heuvel, W. \& Teunisse, S., 2017, Europeana DSI 2 - Access to Digital Resources of European Heritage. D4.4, Report on ENUMERATE Core Survey 4, viewed 15 September 2018, from http://www.den.nl/art/uploads/files/DSI-2 Deliverable $\% 20 D 4$ 4 Europeana_Report $\% 20$ on $\% 20$ ENUMERATE $\% 20$ Core $\% 20$ Survey\%204.pdf.

Page-Shipp, D., 2011, An audit of South African Digitisation Initiatives: Ongoing and planned, National Research Foundation, Pretoria, viewed 10 March 2016, from http://digi.nrf.ac.za/publ/.

Peters, D., Brenzinger, M., Meyer, R., Noble, A. \& Zimmer, N., 2015, 'The digital library in the re-inscription of African cultural heritage', International Federation of Library Associations and Institutions (IFLA) 41(3), 204-210. https://doi.org/ $10.1177 / 0340035215603990$

Pickover, M., 2008, 'The DISA project. Packaging South African heritage as a continuing resource: Content, access, ownership and ideology', IFLA Journal, 34(2), 192-197. https://doi.org/10.1177/034003520809217

Pickover, M. \& Mohale, G., 2013, Report of the South African Digitisation Initiative (SADI) workshop. Digitisation \& digital libraries: Standards, best practices, policies and technical requirements, 27 February-01 March 2013, viewed 10 March 2016, from http://wiredspace.wits.ac.za/bitstream/handle/10539/13074/SADI_Workshop_ Report_March_2013_-_Final2.pdf?sequence=1.

Poll, R., 2010, 'NUMERIC: Statistics for the digitisation of European cultural heritage', Program: Electronic Library and Information Systems 44(2), 122-131. https://doi. org/10.1108/00330331011039481

Ruthven, I. \& Chowdhury, G.G. (eds.), 2015, Cultural heritage information: Access and management, Facet Publishing, Croydon.

SA libraries, n.d., viewed 13 March 2017, from http://www.liasa.org.za/sa-libraries/.

Stroeker, N \& Vogels, R., 2014, Survey report on digitisation in European Cultural Heritage Institutions 2014, viewed 13 March 2016, from http://www. enumerate.eu/fileadmin/ENUMERATE/documents/ENUMERATE-DigitisationSurvey-2014.pdf.

Sula, C.A., 2015, 'Digital humanities and digital cultural heritage (alt-history and future directions)', in I. Ruthven \& G.G. Chowdhury (eds.), Cultural heritage information: Access and management, pp.13-36, Facet, London.

Terras, M., 2015a, 'Cultural heritage information: Artefacts and digitization technologies', in I. Ruthven \& G.G. Chowdhury (eds.), Cultural Heritage Information: Access and Management, pp. 63-88, Facet, London.

Terras, M., 2015b, 'Opening access to collections: The making and using of open digitised cultural content', Online Information Review 39(5), 733-752. https://doi. org/10.1108/OIR-06-2015-0193

The United Nations Educational, Scientific and Cultural Organization (UNIESCO), 2002, Memory of the World: General guidelines to safeguard documentary heritage, Revised edn., Prepared for UNESCO by Ray Edmondson, Information Society Division, UNESCO, Paris, viewed 18 February 2016, from http://unesdoc.unesco. org/images/0012/001256/125637e.pdf. 
The United Nations Educational, Scientific and Cultural Organization (UNIESCO), 2003a, Convention for the safeguarding of the intangible cultural heritage, UNESCO, Paris, viewed 09 February 2016, from http://unesdoc.unesco.org/ images/0013/001325/132540e.pdf.

The United Nations Educational, Scientific and Cultural Organization (UNIESCO), 2003b, Guidelines for the preservation of digital heritage, Prepared by the National Library of Australia, viewed 09 July 2016, from http://unesdoc unesco. org/images/0013/001300/130071e.pdf.

The United Nations Educational, Scientific and Cultural Organization (UNIESCO), 2015, Transforming our world: The 2030 agenda for sustainable development, A/ RES/70/1, viewed 12 August 2017, from https://sustainabledevelopment un org/ content/documents/21252030\%20Agenda $\% 20$ for $\% 20$ Sustainable $\% 20$ Development\%20web.pdf.

The United Nations Educational, Scientific and Cultural Organization (UNIESCO), 2016a Communication and information: Open Access to scientific information, viewed 18 April 2016, from http://www.unesco.org/new/en/communication-and-information/ access-to-knowledge/open-access-to-scientific-information/.

The United Nations Educational, Scientific and Cultural Organization (UNIESCO) 2016b, Tangible cultural heritage, viewed 09 February 2016, from http://www. unesco.org/new/en/cairo/culture/tangible-cultural-heritage/.
UNESCO/PERSIST Content Task Force, 2016, The UNESCO/PERSIST guidelines for the selection of digital heritage for long-term preservation, viewed 27 February 2017 , from https://www.ifla.org/publications/node/91844.

Western Cape Government (WCG), 2017, Connecting citizens in the Western Cape State of the Province Address (SOPA) 2017, viewed 04 December 2017, from https://www.westerncape.gov.za/general-publication/2017-state-provinceaddress?toc_page $=3$.

Western Cape Government (WCG), Department of Cultural Affairs and Sport (DCAS) 2017, Facilities, viewed 13 March 2017, from https://www.westerncape.gov.za/ dept/cas.

Western Cape Government (WCG), Department Cultural Affairs and Sport (DCAS), Western Cape Archives and Record Service (WCARS), 2017, Digitisation Policy of Western Cape Governmental Bodies 2017, viewed 07 November 2017, from https://www.westerncape.gov.za/assets/departments/cultural-affairs-sport/ digitisation_policy_of_western_cape_bodies_2017_pdf_.pdf.

Zorich, D.M., 2003, A survey of digital cultural heritage initiatives and their sustainability concerns. Managing economic challenges, Council on Library and Information Resources, Washington, DC, viewed 12 March 2016, from https://www.clir.org/ wp-content/uploads/sites/6/pub118.pdf. 